\title{
FORMULATION DEVELOPMENT AND EVALUATION OF DILTIAZEM HYDROCHLORIDE GASTRO RETENTIVE FLOATING TABLETS
}

\author{
Patel Hardik*, Manish Jaimini \\ Department of Pharmaceutics, Jaipur College of Pharmacy, Sitapura-302022, Jaipur, Rajasthan \\ *Correspondence Author's E-mail: hardikpatel36@yahoo.co.in
}

\begin{abstract}
The investigation was concerned with design and characterization of oral sustained release gastro retentive floating tablets of DiltiazemHCl in order to improve efficacy and better patient compliance. Present investigation was to formulate, evaluate and optimize gastro retentive tablet of DiltiazemHCl. This tablets released drug till $24 \mathrm{hrs}$ due to floating mechanism of polymers. Gastro retentive floating tablets were prepared by direct compression method using various proportions of polymersHPMC K4M, HPMC K100M,Carbopol 934, Ethyl cellulose, Xanthan gum along with Sodium bicarbonatethe sustained release behaviour of the fabricated tablets was investigated. Tablets were prepared by directcompretiontechnique.Formulation was optimized on the basis of acceptable tablet properties and in vitro drug release. The resulting formulation produced robust tablets with optimum hardness, consistent weight uniformity and low friability. All tablets but one exhibited gradual and nearcomplete sustained release for DiltiazemHCl (90-100\%) at the end of $24 \mathrm{~h}$. The results of dissolution studies indicated that formulation Dtz15 was found to be most successful as it exhibits drug release pattern very close to theoretical release profile. A decrease in release kinetics of the drug was observed on increasing polymer ratio.

Key Words: Sustained release, Gastro retentive floating, Diltiazim HCL, HPMC K100M, Carbopol 934.
\end{abstract}

\section{INTRODUCTION}

The oral route is considered as the most promising route of drug delivery. Conventional drug delivery system achieves as well as maintains the drug concentration within the therapeutically effective range needed for treatment, only when taken several times a day. This results in a significant fluctuation in drug levels. The most important objectives of these new drug delivery systems are: first, it would be single dose, which releases the active ingredient over an extended period of time. Second, it should deliver the active entity directly to the site of action, thus, minimizing or eliminating side effects. To overcome the limitations of conventional drug delivery system, floating tablets have been developed. Drugs that have narrow absorption window in the gastrointestinal tract will have poor absorption. For these drugs, gastro retentive drug delivery systems offer the advantages in prolonging the gastric emptying time.

\section{MATERIALS AND METHODS}

DiltiazemHCl was gift sample from Devi's laboratories Ltd, India andHydroxypropyl methyl cellulose K4M (HPMC K4M) from Colorcon Asia Pvt.Limited, Goa, India and Hydroxypropyl methyl cellulose K100M (HPMC K100M) from Colorcon Asia Pvt. Limited, Goa, India and Carbopol 934S. D. Fine Chemicals Ltd. Mumbai, India and Ethyl cellulose Asha cellulose Pvt. Ltd, India and Xanthan gum from Otto ChemicaBiochemica Reagents, India and Sodium bicarbonate, Lactose and Hydrochloride Acid obtained from Finar chemicals, Ahmadabad, India and Micro crystalline cellulose (MCC) obtained from Acme pharmaceuticals, Kherva (Gujarat), India and Talc and Magnesium stearate obtained from S. D. Fine Chemicals Ltd. Mumbai, India.

Method forpreparation of DiltiazemHCL floating tablets
All the ingredients weigh accurately the required quantity and mix thoroughly to get uniform powder blend passed through 60 \# sieve. Talc and Magnesium stearate were finally added as glidant and lubricant respectively and finally compressed with the help ofrimek mini tablet press II MT.

\section{FORMULATION}

Preliminary trials of DiltiazemHCl formulation: In present investigation attempt was made to prepare sustained (gastro retentive layer) release formulation of diltiazemHCl using different grades of HPMC, ethyl cellulose, xanthan gum and carbopol as polymers by direct compression techniques using rimek mini tablet press machine.

In preliminary study, different batches were prepared as per the composition given in Table 1. It was found that the batches Dtz3, Dtz4 and Dtz6 show the premature drug release in the initial first hour. That may be due to disintegration of the tablet before the gel formation occurs by the polymer. Batches Dtz1, Dtz2, Dtz5 and Dtz8 shows the release retardation up to some extends but that was not up to the $24 \mathrm{hrs}$. Batch Dtz7 shows the good release retardation but the drug release in the first hour is higher due to the burst release of the drug. This initial burst release may be occurs due to the rapid hydration of the polymer (HPMC K100M)which is hydrophilic in nature. While the dissolution study of batch Dtz9 shows the decrease in initial burst release of the drug and sustained effect up to $24.0 \mathrm{hrs}$ having $98.88 \%$ releases at the end of $24.0 \mathrm{hrs}$. The combination of HPMC K100M and carbopol-934 forms the gel having the higher viscosity that may be responsible for the decrease in initial burst release of drug and for the sustained effect up to $24 \mathrm{hrs}$. Therefore, the composition of batch Dtz9 was selected for further work. 
Table 1: Preliminary trial formulation for DiltiazemHCl tablets

\begin{tabular}{|c|c|c|c|c|c|c|c|c|c|}
\hline \multirow{2}{*}{ Ingredient } & \multicolumn{9}{|c|}{ Batches } \\
\cline { 2 - 10 } & Dtz1 & Dtz2 & Dtz3 & Dtz4 & Dtz5 & Dtz6 & Dtz7 & Dtz8 & Dtz9 \\
\hline DiltiazemHCI & 120 & 120 & 120 & 120 & 120 & 120 & 120 & 120 & 120 \\
\hline HPMC K4M & 75 & - & - & - & - & - & - & 20 & - \\
\hline HPMC K100M & - & 75 & - & - & 55 & 35 & 100 & 80 & 80 \\
\hline Ethyl cellulose & - & - & 75 & - & 40 & 40 & - & - & - \\
\hline Xanthan gum & - & - & - & 75 & - & - & - & - & - \\
\hline Carbopol-934 & - & - & - & - & - & - & - & - & 20 \\
\hline NaHCO3 & 50 & 50 & 50 & 50 & 50 & 50 & 50 & 50 & 50 \\
\hline MCC & 100 & 100 & 100 & 100 & 100 & 100 & 100 & 100 & 100 \\
\hline Lactose & q.s. & q.s. & q.s. & q.s. & q.s. & q.s. & q.s. & q.s. & q.s. \\
\hline Mg Stearate & 5 & 5 & 5 & 5 & 5 & 5 & 5 & 5 & 5 \\
\hline Talc & 10 & 10 & 10 & 10 & 10 & 10 & 10 & 10 & 10 \\
\hline Total wt. & 500 & 500 & 500 & 500 & 500 & 500 & 500 & 500 & 500 \\
\hline
\end{tabular}

Optimization of tablet formulation using $3^{2}$ full factorial designs: It is desirable to develop an acceptable pharmaceutical formulation in shortest possible time using minimum number of man-hours and raw materials. Traditionally pharmaceutical formulations are developed by changing one variable at a time approach. The method is time consuming in nature and requires a lot of imaginative efforts. Moreover, it may be difficult to develop an ideal formulation using this classical technique since the joint effects of independent variables are not considered. It is therefore very essential to understand the complexity of pharmaceutical formulations by using established statistical tools such as factorial design. In addition to the art of formulation, the technique of factorial design is an effective method of indicating the relative significance of a number of variables and their interactions.

The number of experiments required for these studies is dependent on the number of independent variables selected. The response $\left(\mathrm{Y}_{\mathrm{i}}\right)$ is measured for each trial.

$$
Y=b_{0}+b_{1} X_{1}+b_{2} X_{2}+b_{12} X_{1} X_{2}+b_{11} X_{1}^{2}+b_{22} X_{2}^{2}
$$

Where $\mathrm{Y}$ is the dependent variable, $\mathrm{b}_{0}$ is the arithmetic mean response of the nine runs and $b_{i}$ is the estimated coefficient for the factor $\mathrm{X}_{\mathrm{i}}$. The main effects $\left(\mathrm{X}_{1}\right.$ and $\left.\mathrm{X}_{2}\right)$ represent the average result of changing one factor at a time from its low to high value. The interaction terms $\left(\mathrm{X}_{1} \mathrm{X}_{2}\right)$ show how the response changes when two factors are simultaneously changed.

A $3^{2}$ randomized full factorial design was utilized in the present study. In this design two factors were evaluated, each at three levels, and experimental trials were carried out at all nine possible combinations. The design layout and coded value of independent factor is shown in Table 2 and Table 3 respectively. The factors were selected based on preliminary study. The Content of HPMCK100M ( $\mathrm{X}_{1}$ ) and Content of Carbopol-934 (X $)_{2}$ were selected as independent variables.

The selected dependent variables are given below:

$\mathrm{Y}_{1}=$ Cumulative percentage release $(\mathrm{CPR})$ at $1 \mathrm{hr}\left(\mathrm{Q}_{1}\right)$

$\mathrm{Y}_{2}=$ Cumulative percentage release $(\mathrm{CPR})$ at $16 \mathrm{hr}\left(\mathrm{Q}_{16}\right)$

$\mathrm{Y}_{3}=$ Floating lag time study in seconds (FLT)

(C) 2011, JDDT. All Rights Reserved
The formulations of the factorial batches (Dtz9 to Dtz17) are shown in Table 4.

Table 2: Full factorial design Layout

\begin{tabular}{|c|c|c|}
\hline Batch code & $\mathbf{X}_{\mathbf{1}}$ & $\mathbf{X}_{\mathbf{2}}$ \\
\hline Dtz9 & -1 & -1 \\
\hline Dtz10 & -1 & 0 \\
\hline Dtz11 & -1 & 1 \\
\hline Dtz12 & 0 & -1 \\
\hline Dtz13 & 0 & 0 \\
\hline Dtz14 & 0 & 1 \\
\hline Dtz15 & 1 & -1 \\
\hline Dtz16 & 1 & 0 \\
\hline Dtz17 & 1 & 1 \\
\hline
\end{tabular}

Table 3: Coded values for content of HPMC K100M \& content of carbopol-934

\begin{tabular}{|c|c|c|}
\hline $\begin{array}{c}\text { Coded } \\
\text { value }\end{array}$ & $\begin{array}{c}\text { Content of } \\
\text { HPMCK100M (mg) } \\
\mathbf{X}_{\mathbf{1}}\end{array}$ & $\begin{array}{c}\text { Content of } \\
\text { carbopol-934 (mg) } \\
\mathbf{X}_{\mathbf{2}}\end{array}$ \\
\hline-1 & 80 & 20 \\
\hline 0 & 100 & 30 \\
\hline 1 & 120 & 40 \\
\hline
\end{tabular}

On the basis of the preliminary trials in the present study a $3^{2}$ full factorial design was employed to study the effect of independent variables, i.e. content of HPMC $\operatorname{K100M}\left(X_{1}\right)$ and content of carbopol $\left(X_{2}\right)$ on dependent variables like \%drug release at $1 \mathrm{hr} .\left(\mathrm{Q}_{1}\right)$, \%drug release at $16 \mathrm{hr} .\left(\mathrm{Q}_{16}\right)$, \& floating lag time.The results clearly indicate that all the dependent variables are strongly dependent on the selected independent variables as they show a wide variation among the nine batches (Dtz9 to Dtz17).The fitted equations (full models) relating the responses (i.e. $\mathrm{Q}_{1}, \mathrm{Q}_{16} \& \mathrm{FLT}$ ) to the transformed factor were shown in Table 4. The polynomial equation can be used to draw conclusions after considering the magnitude of coefficient and the mathematical sign it carries, i.e. positive or negative. The values of the coefficient are shown in Table 5. and the polynomial equations can be obtained as follows by using the values of coefficient. 
Table 4: Effect of Independent variable on dependent variable by $3^{2}$ full factorial design for DiltiazemHCl

\begin{tabular}{|c|c|c|c|c|c|}
\hline \multirow[t]{2}{*}{ Formulation code } & \multicolumn{2}{|c|}{ Independent variable } & \multicolumn{3}{|c|}{ Dependent variables } \\
\hline & $\mathbf{X}_{1}$ & $\mathbf{X}_{2}$ & $\mathbf{Q}_{1}$ & $\mathbf{Q}_{16}$ & FLT(sec.) \\
\hline Dtz9 & -1 & -1 & 16.99 & 87.98 & 157 \\
\hline Dtz10 & -1 & 0 & 15.30 & 87.92 & 168 \\
\hline Dtz11 & -1 & +1 & 14.45 & 85.19 & 181 \\
\hline Dtz12 & 0 & -1 & 16.81 & 83.68 & 169 \\
\hline Dtz13 & 0 & 0 & 15.97 & 80.78 & 177 \\
\hline Dtz14 & 0 & +1 & 13.44 & 79.54 & 180 \\
\hline Dtz15 & +1 & -1 & 16.80 & 74.51 & 184 \\
\hline Dtz16 & +1 & 0 & 12.20 & 74.96 & 195 \\
\hline Dtz17 & +1 & +1 & 12.11 & 73.25 & 207 \\
\hline
\end{tabular}

Table 5: Summary of regression analysis

\begin{tabular}{|c|c|c|c|}
\hline Coefficients & $\mathbf{Q}_{\mathbf{1}}$ & $\mathbf{Q}_{\mathbf{1 6}}$ & FLT \\
\hline $\mathbf{b}_{\mathbf{0}}$ & 15 & 81.68 & 175.55 \\
\hline $\mathbf{b}_{\mathbf{1}}$ & -0.9383 & -6.395 & 13.33 \\
\hline $\mathbf{b}_{\mathbf{2}}$ & -1.7666 & -1.365 & 9.66 \\
\hline $\mathbf{b}_{\mathbf{1 2}}$ & -0.5375 & 0.3825 & -0.25 \\
\hline $\mathbf{b}_{\mathbf{1 1}}$ & -0.765 & -0.6983 & 6.66 \\
\hline $\mathbf{b}_{\mathbf{2 2}}$ & 0.61 & -0.5283 & -0.33 \\
\hline $\mathbf{R}^{\mathbf{2}}$ & 0.8925 & 0.9871 & 0.9679 \\
\hline
\end{tabular}

$Q_{l}=15-0.9383 X_{1}-1.7666 X_{2}-0.5375 X_{I} X_{2}-0.765 X_{1}^{2}+0.61 X_{2}^{2}(2)$

$Q_{16}=81.68-6.395 X_{1}-1.365 X_{2}+0.3825 X_{1} X_{2}-0.6983_{1}^{2}-0.5283 X_{2}^{2}(3)$

$F L T=175.55+13.33 X_{1}+9.66 X_{2}-0.25 X_{1} X_{2}+6.66 X_{1}^{2}+0.33 X_{2}^{2}(4)$

Table 6: Formulation using $3^{2}$ full factorial designs

\begin{tabular}{|c|c|c|c|c|c|c|c|c|c|}
\hline \multirow{2}{*}{ Ingredients } & \multicolumn{9}{|c|}{ Batches } \\
\hline & Dtz9 & Dtz10 & Dtz11 & Dtz12 & Dtz13 & Dtz14 & Dtz15 & Dtz16 & Dtz17 \\
\hline DitiazemHCl & 120 & 120 & 120 & 120 & 120 & 120 & 120 & 120 & 120 \\
\hline HPMCK10M & 80 & 80 & 80 & 100 & 100 & 100 & 120 & 120 & 120 \\
\hline Carbopol-934 & 20 & 30 & 40 & 20 & 30 & 40 & 20 & 30 & 40 \\
\hline $\mathrm{NaHCO}_{3}$ & 50 & 50 & 50 & 50 & 50 & 50 & 50 & 50 & 50 \\
\hline MCC & 100 & 100 & 100 & 100 & 100 & 100 & 100 & 100 & 100 \\
\hline Lactose & q.s. & q.s. & q.s. & q.s. & q.s. & q.s. & q.s. & q.s. & q.s. \\
\hline Mg. stearate & 5 & 5 & 5 & 5 & 5 & 5 & 5 & 5 & 5 \\
\hline Talc & 10 & 10 & 10 & 10 & 10 & 10 & 10 & 10 & 10 \\
\hline Total weight & 500 & 500 & 500 & 500 & 500 & 500 & 500 & 500 & 500 \\
\hline
\end{tabular}

* All the ingredients are in $\mathrm{mg}$.

\section{EVALUATION OF BLEND:}

a) Bulk density: Weight accurately the powder drug, which was previously passed through 20\# sieve and transferred in $100 \mathrm{ml}$ graduated cylinder. The powder was carefully level without compacting, and read the unsettled apparent volume. The apparent bulk density was calculated in $\mathrm{gm} / \mathrm{ml}$.

b) Tapped density: Accurately weighed the powder drug, which was previously passed through $20 \#$ sieve and transferred in $100 \mathrm{ml}$ graduated cylinder. Initial volume was observed. The cylinder was tapped up to constant volume. c) Compressibility index: The compressibility of the powder was determined by the Carr's compressibility index using the following formula.

$$
\text { Carr's index }=\frac{[(T D-L D) \times 100]}{T D}
$$

Where, TD-tapped density and LD-loose bulk density

d) Hausner's ratio: The Hausner's ratio is a number that is correlated to the flowability of a powder material.

$$
\text { Hausner' sratio }=\frac{T D}{B D}
$$

5) Angle of repose: The angle of repose of powder blend was determined by funnel method. Accurately weighed powder drug was taken in a funnel. Height of the funnel was adjusted in such ways that tip of the funnel just ISSN: 2250-1177

CODEN (USA): JDDTAO 
touches the apex of the powder drug. The powder mix was allowed to flow through the funnel freely onto the surface. The diameter of the powder cone was measured and angle of repose was calculated using the following equation;

$$
\tan \theta=\frac{h}{r}
$$

Where, $\mathrm{h}$ and $r$ are the height and radius of the powder cone.

Table No. 7: Physical properties of powder blend containing DiltiazemHCl

\begin{tabular}{|c|c|c|c|c|c|}
\hline Formulation code & $\begin{array}{c}\text { Bulk density } \\
(\mathbf{g m} / \mathbf{m l})\end{array}$ & $\begin{array}{c}\text { Tapped density } \\
(\mathbf{g m} / \mathbf{m l})\end{array}$ & $\begin{array}{c}\text { Angle of } \\
\text { Repose }(\boldsymbol{\theta})\end{array}$ & Hausner's ratio & $\begin{array}{c}\text { Percentage } \\
\text { compressibility }\end{array}$ \\
\hline Dtz9 & $0.355 \pm 0.02$ & $0.390 \pm 0.04$ & $34.9 \pm 0.02$ & $1.09 \pm 0.03$ & $10.25 \pm 0.02$ \\
\hline Dtz10 & $0.327 \pm 0.03$ & $0.360 \pm 0.03$ & $29.23 \pm 0.02$ & $1.10 \pm 0.02$ & $9.1 \pm 0.03$ \\
\hline Dtz11 & $0.331 \pm 0.04$ & $0.365 \pm 0.02$ & $28.36 \pm 0.01$ & $1.10 \pm 0.03$ & $9.31 \pm 0.03$ \\
\hline Dtz12 & $0.194 \pm 0.03$ & $0.218 \pm 0.04$ & $34.23 \pm 0.02$ & $1.12 \pm 0.03$ & $11 \pm 0.02$ \\
\hline Dtz13 & $0.296 \pm 0.03$ & $0.323 \pm 0.06$ & $32.12 \pm 0.03$ & $1.09 \pm 0.04$ & $8.3 \pm 0.03$ \\
\hline Dtz14 & $0.250 \pm 0.02$ & $0.269 \pm 0.02$ & $31.89 \pm 0.01$ & $1.07 \pm 0.02$ & $7.06 \pm 0.04$ \\
\hline Dtz15 & $0.260 \pm 0.04$ & $0.290 \pm 0.03$ & $32.49 \pm 0.03$ & $1.11 \pm 0.04$ & $10.34 \pm 0.04$ \\
\hline Dtz16 & $0.246 \pm 0.04$ & $0.265 \pm 0.02$ & $31.87 \pm 0.02$ & $1.07 \pm 0.03$ & $7.31 \pm 0.03$ \\
\hline Dtz17 & $0.276 \pm 0.03$ & $0.300 \pm 0.04$ & $34.12 \pm 0.04$ & $1.08 \pm 0.02$ & $8 \pm 0.02$ \\
\hline
\end{tabular}

\section{EVALUATION OF FORMULATED TABLET}

\section{Weight variation}

20 tablets were selected randomly from the lot and weighed individually to check for weight variation. Weight variation specification as per I.P.

Table 8: Weight Variation Specification as per IP

\begin{tabular}{|c|c|}
\hline Average Weight of Tablet & \% Deviation \\
\hline $\mathbf{8 0}$ mg or less & \pm 10 \\
\hline $\begin{array}{c}\text { More than 80 mg but less } \\
\text { than 250 mg }\end{array}$ & \pm 7.5 \\
\hline 250 mg or more & \pm 5 \\
\hline
\end{tabular}

\section{Hardness}

Hardness or tablet crushing strength $\left(\mathrm{f}_{\mathrm{c}}\right)$ (the force required to break a tablet in a diametric compression) was measured using Monsanto tablet hardness tester. It is expressed in $\mathrm{kg} / \mathrm{cm}^{2}$.

\section{Friability (F)}

Friability of the tablet determined using Roche friabiltor. This device subjects the tablet to the combined effect of abrasion and shock in a plastic chamber revolving at 25rpm and dropping a tablet at 1 height of 6 inches in each revolution. Preweighted sample of tablets was placed in the friabilator and were subjected to the 100 revolutions. Tablets were de-dusted using a soft muslin cloth and reweighed. The friability $(\mathrm{F})$ is given by the formula.

$$
F=\frac{W(\text { initial })-W(\text { final })}{W(\text { initial })} * 100
$$

Table 9: Physical parameters of prepared tablet containingDiltiazemHCl

\begin{tabular}{|c|c|c|c|c|}
\hline Bathes & Weight variation $\mathbf{( m g )}$ & Hardness $\mathbf{( k g / \mathbf { c m } ^ { 2 } )}$ & \%Friability & Drug content \\
\hline Dtz9 & $497 \pm 2.78$ & $5.7 \pm 0.18$ & $0.77 \pm 0.08$ & $100.52 \pm 1.24$ \\
\hline Dtz10 & $500 \pm 2.95$ & $5.6 \pm 0.39$ & $0.85 \pm 0.07$ & $99.32 \pm 1.86$ \\
\hline Dtz11 & $496 \pm 2.58$ & $5.8 \pm 0.47$ & $0.67 \pm 0.04$ & $99.01 \pm 1.40$ \\
\hline Dtz12 & $503 \pm 2.45$ & $5.6 \pm 0.35$ & $0.87 \pm 0.03$ & $101.09 \pm 1.96$ \\
\hline Dtz13 & $496 \pm 2.37$ & $5.8 \pm 0.24$ & $0.74 \pm 0.10$ & $99.74 \pm 1.34$ \\
\hline Dtz14 & $503 \pm 2.75$ & $5.9 \pm 0.14$ & $0.86 \pm 0.09$ & $100.57 \pm 1.21$ \\
\hline Dtz15 & $500 \pm 2.78$ & $5.7 \pm 0.48$ & $0.79 \pm 0.05$ & $100.04 \pm 1.15$ \\
\hline Dtz16 & $496 \pm 2.86$ & $6.0 \pm 0.34$ & $0.95 \pm 0.03$ & $98.75 \pm 2.32$ \\
\hline Dtz17 & $502 \pm 2.77$ & $6.1 \pm 0.27$ & $0.74 \pm 0.07$ & $97.33 \pm 3.83$ \\
\hline
\end{tabular}

All the tablet formulations showed acceptable physical parameters and complied with the in house specifications for weight variation, hardness and friability. Results are shown in Table 9. Hardness above 3 to $5 \mathrm{~kg} / \mathrm{cm}^{2}$ is sufficient to prevent breaking of tablets in handling as well as during packaging. Friability below $1 \%$ prevents loss of material during handling. Weight variation is also 
important consideration, which is ultimately responsible for content uniformity.

In vitro buoyancy studies:In vitro buoyancy studies of all factorial design batches were carried out as per the procedure given before. All the different formulation has floating lag time less than 4 minutes. The pictorial results of in vitro buoyancy study of the best batch are shown in Figure 1. This clearly depicts the floating lag time, stable and persistent buoyancy.All the preliminary trial batches were containing different concentration of polymer blend in order to optimize content of polymer blend for desirable floating time and floating lag time.

Table 10: Floating lag time and floating time of formulation:

\begin{tabular}{|c|c|c|c|c|c|c|c|c|c|}
\hline Parameters & Dtz9 & Dtz10 & Dtz11 & Dtz12 & Dtz13 & Dtz14 & Dtz15 & Dtz16 & Dtz17 \\
\hline $\begin{array}{c}\text { Floating lag } \\
\text { time(sec.) }\end{array}$ & 157 & 168 & 181 & 169 & 177 & 180 & 184 & 195 & 207 \\
\hline Floating time (hr.) & $>24$ & $>24$ & $>24$ & $>24$ & $>24$ & $>24$ & $>24$ & $>24$ & $>24$ \\
\hline
\end{tabular}

Table 10. shows floating lag time and Floating time of different formulation. Batch Dtz9, containing $16 \%$ of HPMCK100M and 4\% of Carbopol shows good floating time that is more than $24 \mathrm{hrs}$ and floating lag time is 157 sec. Therefore these combinations of polymers were optimized for further study. Other batches Dtz2, Dtz7 and Dtz8 also shows good floating time, which is more, then $24 \mathrm{hrs}$ and also good floating lag time, which is less than 3 minutes. $3^{2}$ factorial design (Dtz9-Dtz17) formulation showing good floating time and fast floating lag time.

\section{Swelling index study}

Tablets composed of polymeric matrices build a gel layer around the tablet core when they come in contact with water. This gel layer governs the drug release. Kinetics of swelling is important because the gel barrier is formed with water penetration.
Table 11: Swelling index study of best batch Dtz7

\begin{tabular}{|c|c|}
\hline Time (hrs) & \% Swelling index \\
\hline 3 & 75.34 \\
\hline 6 & 139.57 \\
\hline 12 & 182.79 \\
\hline 15 & 189.34 \\
\hline 18 & 197.68 \\
\hline 24 & 203.77 \\
\hline
\end{tabular}

Swelling is also vital factor to ensure floating. To obtain floating, the balance between swelling and water acceptance must be restored. The swelling index of the best batch (Dtz15) at different time intervals was mention in Table 11, which may be because of high viscosity and high water retention property of HPMC polymer.

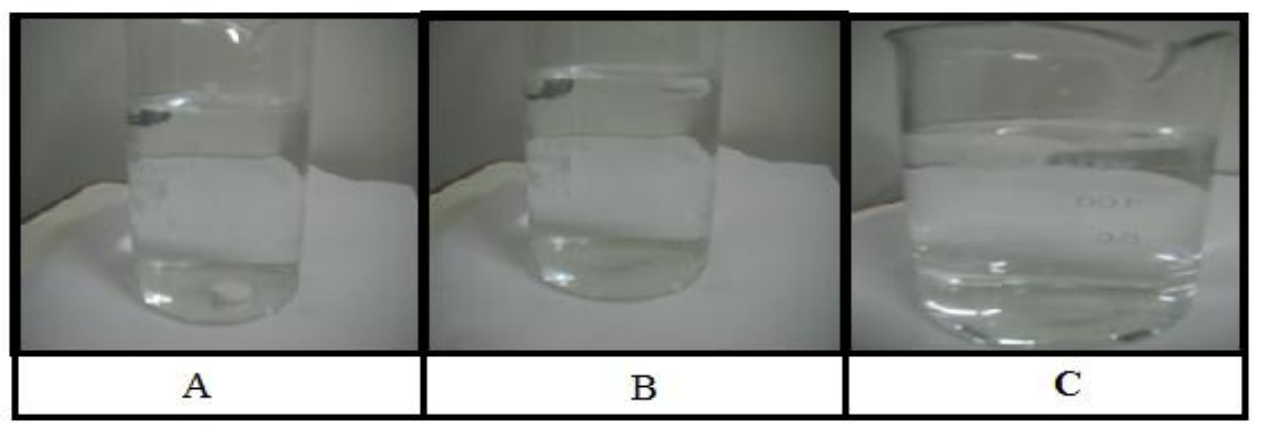

(A) Initially

Figure 1: In vitro buoyancy studies

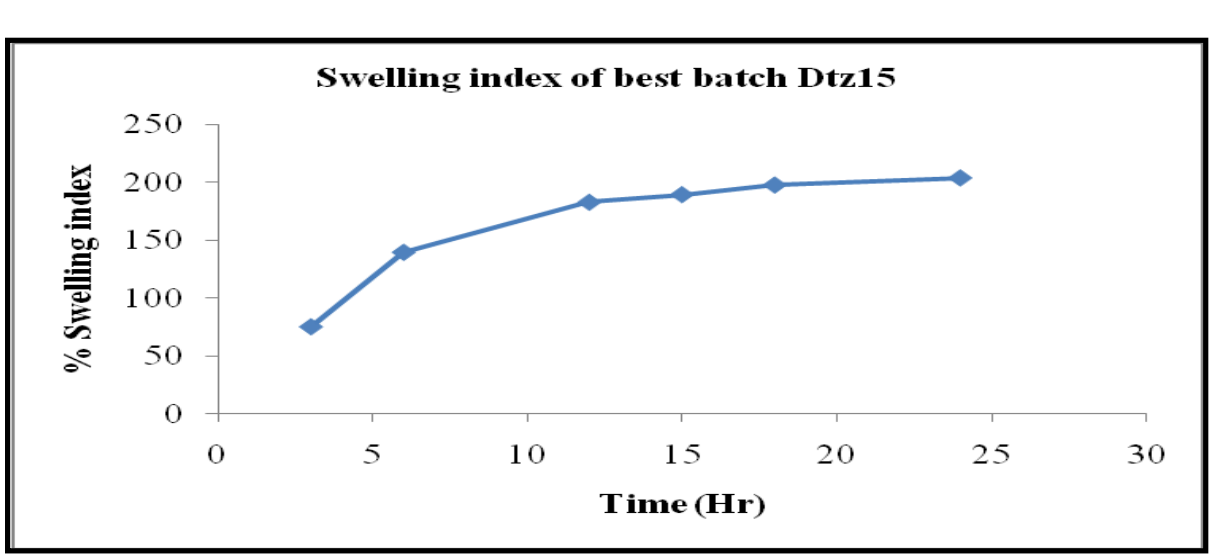

Figure 2: Swelling index of best batch Dtz15 


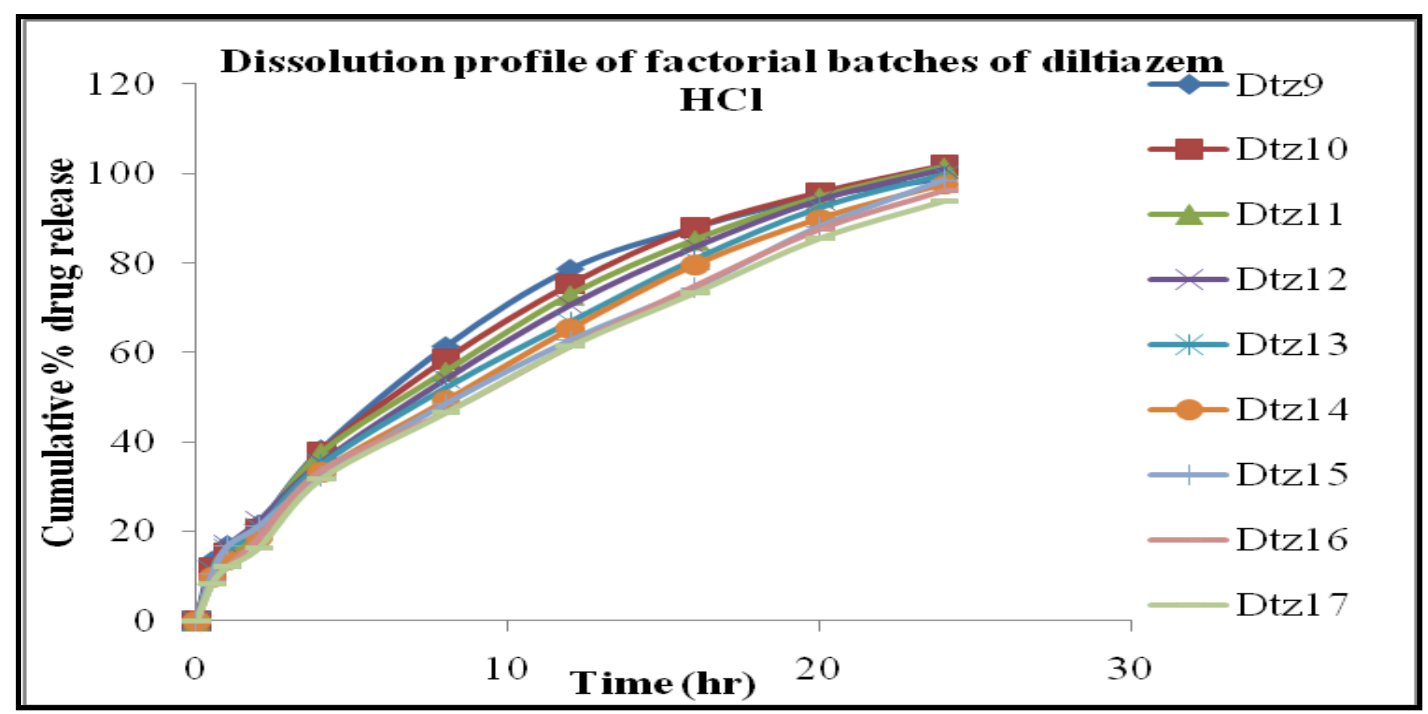

Figure 3: Drug release profile of tablet

\section{Calculation of total dose and theoretical drug release profile}

The pharmacokinetics parameters of diltiazemHCl were used to calculate a theoretical drug release profile for a 24 hrs dosage form. The immediate release dose and maintenance dose of diltiazem $\mathrm{HCl}$ was calculated using equation $1 \& 2$ and was found to be $20.66 \mathrm{mg}$. and 99.06 mg. respectively. Hence, the formulation should release $20.66 \mathrm{mg}(17.21 \%)$ of drug in initial $1.0 \mathrm{hr}$. While in the remaining $23.0 \mathrm{hrs}$ drug release should be $99.06 \mathrm{mg}$. So, every $1 \mathrm{hrs} 4.30 \mathrm{mg}(3.58 \%)$ of drug release till 23.0 hrs. Theoritical release profile is shown in Table 6.9.

\section{Calculation of the loading dose:}

IRD $=\underline{\text { Css } \times \mathrm{Vd} \times \text { Body weight }}$

$\mathrm{F}=20.66 \mathrm{mg} \cong 21.0 \mathrm{mg}$

Calculation of Maintenance Dose (MD)

Maintenance Dose $=$ LD Dose $\left(1+0.693 \times \mathrm{t}_{\mathrm{t}} \mathrm{t}_{\frac{1}{2}}\right)$

$$
=99.06 \mathrm{mg} \cong 99.0 \mathrm{mg}
$$

Total dose $=(21+99) \mathrm{mg}=120 \mathrm{mg}$

Table 12: Theoretical release profile of sustained release layer

\begin{tabular}{|c|c|c|}
\hline Time (hrs) & $\begin{array}{c}\text { Theoretical release } \\
\text { profile \% }\end{array}$ & Range (\%) \\
\hline $\mathbf{0}$ & 0 & 0 \\
\hline $\mathbf{1}$ & 17.24 & $15-20$ \\
\hline $\mathbf{4}$ & 28.12 & $20-35$ \\
\hline $\mathbf{8}$ & 42.50 & $35-50$ \\
\hline $\mathbf{1 2}$ & 56.87 & $45-65$ \\
\hline $\mathbf{1 6}$ & 71.25 & $65-80$ \\
\hline $\mathbf{2 0}$ & 85.62 & NLT 80 \\
\hline $\mathbf{2 4}$ & 99.98 & - \\
\hline
\end{tabular}

\section{Comparison of dissolution profiles}

The similarity factor $\left(f_{2}\right)$ given by SUPAC guidelines for modified release dosage form was used as a basis to compare dissolution profile. The dissolution profiles are considered to be similar when $f_{2}$ is between 50 and 100.The dissolution profiles of products were compared using $f_{2}$. This similarity factor is calculated by following formula,

$$
f_{2}=50 \log \left\{\left[1+\frac{1}{n} \sum_{t=1}^{n}\left(R_{t}-T_{t}\right)^{2}\right]^{-0.5} \times 100\right\}
$$

Where, $\mathrm{n}$ is the number of dissolution time and $\mathrm{R}_{\mathrm{t}}$ and $\mathrm{T}_{\mathrm{t}}$ are the reference and test dissolution values at time $t$.

In vitro drug release profile of all batches of factorial design was compared with theoretical drug release profile. The result is shown in Table 13, which indicates that, the all the batches except the Dtz9 shows good similarity to theoretical release profile. But batch Dtz15 showed the highest $f_{2}$ among all the batches that is 74.76. The similarity between the theoretical release profile and the in vitro drug release profile of Dtz15 is clearly demonstrated in Figure 4. 
Table 13: Similarity factor amongst the factorial batches

\begin{tabular}{|c|c|c|c|c|c|c|c|c|c|}
\hline $\begin{array}{c}\text { Formulation } \\
\text { code }\end{array}$ & Dtz9 & Dtz10 & Dtz11 & Dtz12 & Dtz13 & Dtz14 & Dtz15 & Dtz16 & Dtz17 \\
\hline $\begin{array}{c}\text { Similarity } \\
\text { factor }\left(\mathbf{f}_{2}\right)\end{array}$ & 48.85 & 50.97 & 54.07 & 56.98 & 62.14 & 66.35 & 74.76 & 72.98 & 72.48 \\
\hline
\end{tabular}

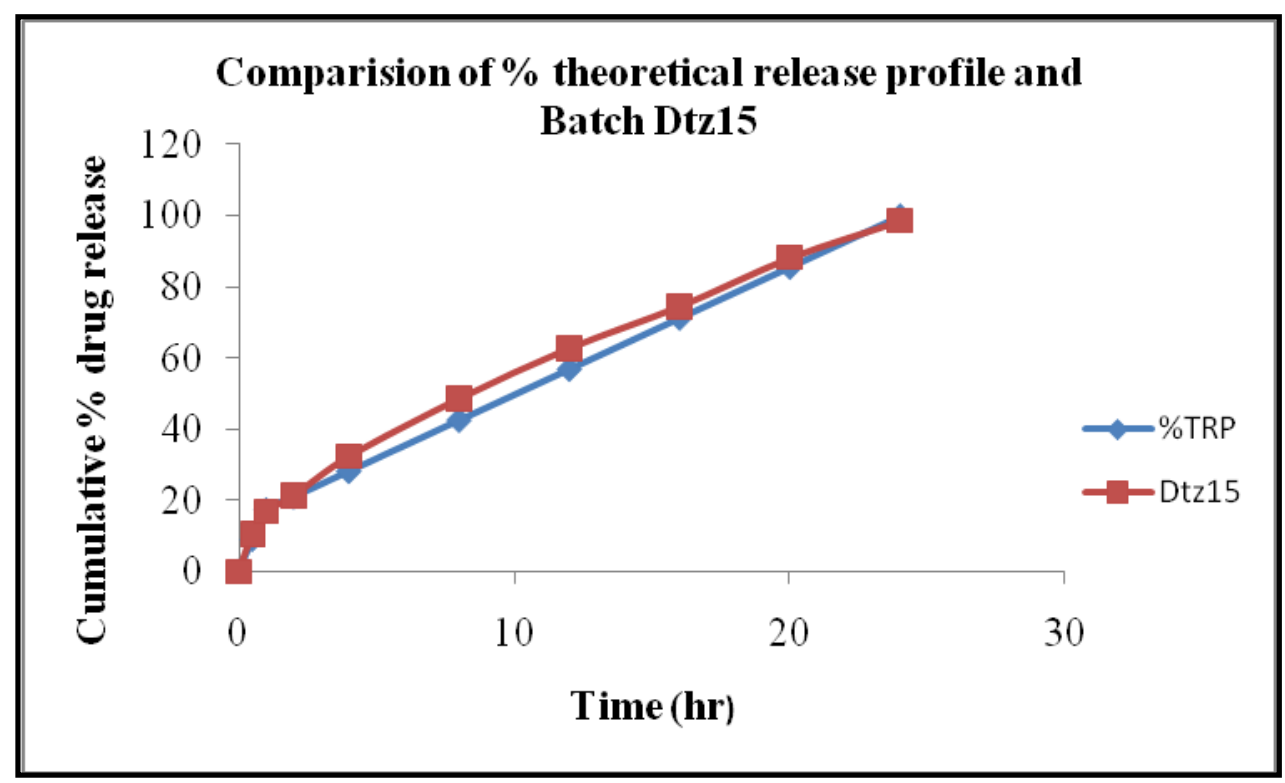

Figure 4: Comparison of theoretical drug release profile and batch Dtz15

Table 14: Comparison of check points between TRP and batch Dtz15

\begin{tabular}{|c|c|c|}
\hline $\begin{array}{c}\text { Check } \\
\text { points }\end{array}$ & $\begin{array}{c}\text { Theoretical } \\
\text { value }\end{array}$ & $\begin{array}{c}\text { Batch } \\
\text { Dtz15 }\end{array}$ \\
\hline $\mathbf{Q}_{\mathbf{1}}$ & 17.24 & 16.80 \\
\hline $\mathbf{Q}_{\mathbf{1 6}}$ & 71.25 & 74.51 \\
\hline $\mathbf{Q}_{\mathbf{2 0}}$ & 85.62 & 88.18 \\
\hline $\mathbf{f}_{\mathbf{2}}$ & $50-100$ & 74.76 \\
\hline
\end{tabular}

The results of comparison of various check points between theoretical values and batch Dtz15 are shown in table 14. The results depicts that the batch Dtz15 shows the good fit with the theoretical values.

\section{RESULT AND DISCUSSION}

In tablet of DiltiazemHCl the loading dose, maintenance dose, and theoretical drug release profile was calculated based on pharmacokinetics data. Loading dose of DiltiazemHCl was released as a burst release from the tablet during the initial polymer hydration and the remaining drug was released up to $24 \mathrm{hrs}$ as a maintenance dose.

A $3^{2}$ full factorial design was applied to systemically optimize in vitro drug release profile. The content of HPMC $\mathrm{K} 100 \mathrm{M}\left(\mathrm{X}_{1}\right)$ and content of carbopol $\left(\mathrm{X}_{2}\right)$ were selected as independent variables. The cumulative $\%$ drug release at $1 \mathrm{hr}\left(\mathrm{Q}_{1}\right)$, cumulative $\%$ drug release at $16 \mathrm{hr}\left(\mathrm{Q}_{16}\right)$, floating lag time was selected as dependent variables. The result of full factorial design was indicated that the $\mathrm{X}_{1}$ (content of HPMC K100M) and $\mathrm{X}_{2}$ (content of carbopol) both have significant effect on in vitro drug release profile.

As the concentration of carbopol\& conc. of HPMC K100M increases, the release of drug is retarded due to entrapment of drug molecules in the close proximity ofcarbopol\& HPMC K100M. Use of HPMC K100M \&carbopol was an advantageous combination for formulating gastro retentive tablet. Concentration of HPMCK100M was optimized which was 24\% (120 mg). Concentration of carbopol was optimized which was $4 \%$ (20 mg). Floating lag time of all factroialbatchs was less than four minutes. From, in vitro dissolution study it was observed that batch Dtz15 releases $98.56 \%$ of drug in 24 $\mathrm{hr}$ with floating lag time of 184 seconds. The similarity factor $f_{2}$ was applied between the in vitro drug release profile of factorial design batches and theoretical drug release profile. No significant difference was observed between desired release profile and batches Dtz10 to Dtz17. Batch Dtz15 showed highest $f_{2}\left(f_{2}=74.76\right)$ among all the batches. Data of kinetic modeling showed that drug release mechanism was best explained by higuchi plot and value of $n(=0.57)$ indicates the anomalous transport i.e. a combined mechanism of pure diffusion and swellingcontrolled drug release.

Thus it was summarized and concluded that gastro retentive tablet of diltiazemHClcan be successfully formulated with HPMC K100M and carbopol-934. 


\section{REFERENCES}

1. Abrahamsson B, Alpsten M, and Hugosson M. Absorption gastrointestinal transit and tablet erosion of felodipine extended release (ER) tablets. Pharm Res 1993; 10:709-714.

2. Agyilirah GA, Green M, Ducret R. Evaluation of the gastric retention properties of a cross linked polymer coated tablet versus those of a non-disintegrating tablets. Int J Pharm 1991; 75: 241-247.

3. Akbari BV, Valaki BP, Maradiya V H, AkbariAK.Enhancement of solubility and dissolution rate of rosuvastatin calcium by complexation with $\beta$-cyclodextrin.Int J Pharm \&Biol 2011; 2(1): 492-501.

4. Atybi F, Sharma HL, Mohmmad AH, Fell JT. Controled drug release from coated floating ion exchange resin beads. J Control Release 1996; 42:25-28.

5. Aulton ME. The design and manufacture of medicines: pharmaceutical preformulation. $3^{\text {rd }}$ ed.ChurchillLivingstone;2007. p. 355-60.

6. Bandari S, Yamsani MR. Biphasic gastroretentive drug delivery system of acyclovir: Formulation and In Vitro Evaluation. Lat. Am. J. Pharm 2010 Feb29 (7): 1144-51.

7. Venu PR, Sunita RS, Rajesh PA, Naresh G and Hindustan AA. Novel approach in designing tablets of cetirizine $\mathrm{HCl}$. Ind $J$ Pharm Edu Res Jul-Sep2012;46(3): 253-258.

8. Bathool A, Gowda DV, Khan MS, Ahmed A, Vasudha SL, Rohitash K. Development and evolution of microporous osmotic tablet of diltiazemHCl: $J$ of adv pharm tech res Apr-June 2012; 3(2): 124-129.

9. Baumgartner S, Krsti J and Zorko B. Optimisation of floating matrix tabletand evaluation of gastric recidence time. Int J Pharm 2000; 195(1): 125-135.

10. Bechgaard H, Ladefoged K. Distribution of pellets in the gastrointestinal tract: The influence on transit time exerted by density or diameter of pellets. J. Pharm. Pharmacol 1978; 30:690-692.

11. Bennett CE, Hardy JG, Wilson CG. The influence of posture on the gastric emptying of antacids. Int J Pharm 1984; 21:341-347.

12. BF Goodrich Company. Technical literature: Carbopol, Noveon, Pemulen resins handbook 1995

13. Chawla C, Gupta P, Koradia V, Bansal AK, Gastroretention: A means to address regional variability in intestinal drug absorption, Pharm tech 2003; 27: 50-68.

14. Chinam N, Arethi B, Pandit H, Singh SP, Meduri V. Design and evaluation of sustained release bilayer tablets of propranolol hydrochloride.Acta Pharm2007 Aug 20; 57: 479-89.

15. Chueth HR, Zia H, Rhodes CT. Optimization of sotalol floating and bioadhesive extended release tablet formulation. Drug Dev Ind Pharm 1999; 21:1725-1747.

16. Dahl TC, Calderwood $\mathrm{T}$, Bormeth $\mathrm{A}$, et al. Influence of physicochemical properties of hydroxypropyl methylcellulose on naproxen release from sustained release matrix tablets.J Control Release 1990; 14: 1-10.
17. Davis SS, Stockwell SF, Taylor MJ, Hardy JG, Whelley DR. The effect on density on the gastric emptying of single and multiple-unit dosage form. Pharm Res 1986; 3:208-213.

18. Deshpande AA, Shah NH, Rhodes CT, Malick W. Development of a novel controlled release system for gastric retention. Pharm Res 1997;14:815-819.

19. Dhumal RS, Rajmane ST, Dhumal ST, Pawar AP. Bi-layer floating tablets of cefuroxime axetil for bimodal release. JSci Ind Res2006;65(10): 543-548.

20. Dow chemical company. Technical literature: Methocel cellulose ethers in aqueous systems for tablet coating, Drug Dev Ind Pharm 1989; 15: 975-999.

21. Du Q, Fan CS, Preparation and evaluation of floating granules of aminophyllin. Through Chemical Abstract 1996;125(3): 6745

22. Tripathi KD. Essentials of medical pharmacology. $5^{\text {th }}$ ed. Jaypee Brothers Medical Publishers Pvt Ltd. p. 493-498.

23. Fabrcgas JL, Cucala CG, Pous J, Sites RA. In vitro testing of an antacid formulation with prolonged gastric residence time. Drug Dev. Ind. Pharm 1994; 20:1199-1212.

24. Farouk M. A programmable drug delivery system for oral administration. Int J Pharm 1999;184:131-139.

25. Franz M R and Oth M P. Sustained release bilayer buoyant dosage form, US patent, 5,232,704, August 3; 1993.

26. Fujimori J, Machida Y, Nagai T. Preparation of magneticallyresponsive tablet and confirmation of its gastric residence in beagle dogs. Pharm.Sci1994; 4:425-430.

27. Garg R, Gupta GD., Progress in controlled gastroretentive delivery systems, Trop J Pharm res Sep 2008;7(3):1055-1066.

28. Gordon MS, Rudraraju VS, Dani K, Chowhan ZT. Effect of the mode of super disintegrant incorporation on dissolution in wet granulated tablets. J Pharm Sci1993; 82(2): 220-226.

29. Gorman EA, Rhodes CT, Rudnic EM. An evaluation of croscarmellose as a tablet disintegrant in direct compression systems. Drug Dev Ind Pharm 1982;8:397-410.

30. Greminger JK, Krumer K, Davidson, RL. Alkyl and hydroxyalkyl cellulose:Handbook of water soluble gums and resins, McGraw Hill Book Co, New York, 1980,3-25.

31. Griming R, Berntgen M. "Estimation of the gastric residence time magnetic dosage forms using the Heidlberg capsule." Pharmazie 1996;51:328-331.

32. Hoffman F, Pressman JH, Code CF. Controlled entry of orally administered drugs, physiological considerations. Drug Dev Ind. Pharm 1983;9:1077-1085.

33. Hou SYE, Cowles VE, Berner B, Gastric retention dosage form: A review. Crit Rev Ther Drug Carrier Syst 2003;20:461-497.

34. Hwang SJ, Park H. Gastric retentive drug delivery systems. Cri Rev Ther Drug Carr Syst 1998;15:234-284

35. Ichikawa M, Kato T, Kawahara M, watanabe S and Kayano M. A new multiple unit oral floating dosage system. II: In-vivo evaluation of floating and sustained release characteristics with p-amino benzoic acid and Isosorbide dinitrate as model drugs. $J$ Pharm Sci 1991;80:1062-1066, 1153-1156. 